\title{
THE INTERACTION OF USER EXPERIENCES WITH DIGITAL ECONOMY PLATFORMS AND CREATIVE WRITING: EMPIRICAL EVIDENCE FROM INDONESIA
}

\author{
Retno Purwani Sari \\ English Department, Universitas Komputer Indonesia, Bandung, Indonesia
}

\begin{abstract}
The current study investigates how Indonesian user experiences with digital economy platforms support creative writing as a marketing communication strategy. This study employed a crosssectional qualitative research design. At a single point in time, data on the assumptions of research participants were collected using questionnaires. To assess what and how participants shared their experiences and assumptions, interaction analysis was used. Preliminary findings indicate that Indonesian user experiences with digital economy platforms have an impact on the quality and accuracy of their writing. The findings revealed that digital writing principles - language choices, writing styles, and engagement with popular culture - are present in today's creative writing. This implies that a minor change in the marketing message completely alters how and where it is promoted. Creative writing skills and digital literacy are valued in the labor market. These results are useful as a basis for strategic planning in the Indonesian educational system and marketing communication.
\end{abstract}

Keywords: Digital Economy Platforms, User Experiences, Creative Writing

DOI: http://dx.doi.org/10.15549/jeecar.v9i1.868

\section{INTRODUCTION}

In this new economy, digital networking and communications infrastructure offer some platforms for organizations to compete in the digital world. This enables the development of a marketing communication strategy, which includes a message (what should be said), medium selection (where should it be said), and target identification (to whom the message is targeted). For example, when creating a marketing message, a digital content writer carefully considers what to say and how to say it, including marketing content and its spin or angle. These elements are essential for virtually any communication strategy or marketing activity. As a result of this problem, creative writing on digital economy platforms has evolved into a unique skill that must be mastered. Providing this skill to human resources is currently a challenge for educational institutions in Indonesia.

Technology influences the changing nature of today's work and skills in some ways. This technology, according to the Joint Research Center (JRC), is reshaping millions of jobs in the European Union (EU), including those that require specific skills and competencies (Gonzàlez Vàzquez, 2019). Digital and noncognitive skills are required to meet current labor market demands. Speaking of digital economy platforms, Tokopedia, Bukalapak, and Shopee have altered the way industries conduct 
business. They must make some adjustments to fit, such as flexibility, changing demands, and consumer preferences. It encourages businesses to develop an effective marketing strategy. Marketing message creation is one of the issues. In response to the lightning-pace of today's modern markets, the Indonesian educational system has devised a strategy for developing future skills through the "Independent Campus, Freedom to Learn" program designed by the Ministry of Education and Culture of the Republic of Indonesia. The use of digital learning methods benefits creative writing skills, which highlight 21st-century skills. At the same time, a marketing communication strategy is developed using this method.

Meekings (2021) underlines that digital platforms are new educational resources that allow students from various backgrounds, cultures, and linguistic levels, areas of interest, fandoms, genre preferences, and communication styles to compose creative writing. Utilizing common language from apps such as Instagram, Twitter, and Youtube links, assignments, and assessments leads to pre-existing knowledge and capabilities to deal with the new content and thus develop the skills. According to Connoly and Burn (2019), the Story Engine - a prototype online platform - effectively promotes students' creativity and creative writing. While engaging with narratives of the story engine, the students manipulated sentence structure, adjective choices, and vocabulary. In this way, they adapt vernacular styles of popular cultural language. Their literacy levels and digital competencies improve the effectiveness and efficiency of the learning process. Shopova (2014) emphasizes the use of ICT in relation to students' ability to succeed in meeting the ever-changing demands of work and skills.

In terms of pre-existing knowledge in content creation, consumer-generated content has the potential to impact brand equity (BE) by mediating the role of consumer engagement behavior (CEB) (Zailskaite-Jakste and Minelgaite, 2021). It demonstrates how creative writing in digital economy platforms considers consumer engagement. Because customer alignment is critical, content can be thought of as the consumer's attitude (Voss, Spangenberg, Grohmann, 2003). It is regarded as an important component of the marketing communication strategy. Creative writing skills help digital content writers manage their tasks and develop more effective and powerful content for marketing by highlighting the importance of content.

However, contemporary research has not extensively addressed the link and match between educational efforts and market demands. As a result, the current study focuses on how creative writing is created in the content creation industry, promoting a marketing communication strategy. This study offers some empirical assumptions to such resources and suggestions of best methods for learning creative writing because of the need to learn the interplay between user experiences with digital economy platforms and creative writing of a group of digital content writers. For these reasons, it investigates how their experiences support their creative writing, reveals how their knowledge gained from interaction in various digital economy platforms contributes to their innovative products.

In fact, this is not a fringe concern. It responds to Shopova's argument (2014) that students' knowledge and competencies for effective use of the new technology in the learning process are frequently superficial, despite being adept at using social media and surfing the internet. This study investigated the specific experiences of professional digital content writers that help them create content. This aimed at identifying how they have used their experiences and what various factors ensure the success of writing creatively. It is proposed digital technology has altered the nature of writing, requiring the incorporation of digital writing principles into the creative writing process. As novelties, it provides information for developing a specific method for teaching creative writing using digital economy media and strategy to design a marketing communication strategy. To respond to the issue, it used the procedures of the analytic descriptive qualitative method.

\section{LITERATURE REVIEW}

Participation and connecting with others are cases of constructive interaction in online networks and communities (Ratajczak-Mrozek et al., 2021). In a sense, relationships define value creation. As a marketing specialist, a digital content writer must engage consumers by delivering a skillful marketing message through 
his content creation. Consumer-generated content not only affects brand equity; it also provokes consumers to act on the message.

When it comes to crafting an effective marketing message, language choice and style are critical considerations. Because language performs various functions, including persuasive and emotive functions (Halliday and Matthiessen, 2014), it can be used to meet marketing expectations. The powerful combination of language functions benefits the writer's attitude communication while also influencing customer behavior and attitudes. Choosing appropriate language and style in marketing content writing presents both a challenge and opportunity, particularly in today's digital world.

If the motivating effects of writing on screen are involved in this content creation, marketing messages are constructed using a variety of modalities that complement, augment, or replace written representation in various communicative context (Kress, 2003). Writing on the YouTube platform, for example, is concerned with the verbal and symbolic aspects of screenbased text consumption and production (Merchant, 2007).

Every platform, however, is unique and offers a specific set of characteristics and features. While some platforms appreciate the flexibility, digital content writers experience substantial challenge. They must create marketing content that not only presents the CEB (Zailskaite-Jakste and Minelgaite, 2021), but also textually conveys firms' intentions and motives, implying that digital and language literacy aid in message interpretation and production. Furthermore, the evolution of digital economy platforms affects how digital content writers as firms' representatives design competitive strategies, as well as consumers' attitudes (Goldfarb et al., 2015). Consumers can participate through feedback mechanisms on platforms that use language as entry points for digitalized social and economic activities (Lampinen et al., 2018). Consumer engagement is structurally constructed in some ways.

Customers are engaged through interface-level interaction. Dialogic negotiation as humancomputer interaction ( $\mathrm{HCI})$ frame represents what should be said, whether information, direction, or a particular attitude toward what should be communicated. Language use, as previously stated, enacts social relationships in this digital economy activity. The language chosen for its persuasive function (Halliday and Matthiessen, 2014) is drawn from a set of language forms triggered by the user's experiences with such a digital economic platform and economic actors' interpersonal relationships (consumers, the firms, and the digital content writers).

Adopted Kress's ideas (2003), language is not limited to linguistic modes such as words, phrases, and clauses. Other modes of communication can be used to convey a marketing message. Symbolic aspects of a screen-based text, for example, are illustrated using visual images on YouTube platforms. Taking cues from debates about the use of multimodal text (Bearne and Wolstencroft, 2006), words, images, and other elements are used to convey meaning in the greater context. Interestingly, digital music and digital photography have grown to be important and powerful communicative tools (Merchant, 2007). Various verbal and visual modes are exploited on the YouTube page to present marketing messages. Letters, a linguistic form, icons, visual features, and digital music all contribute to the creation of corporate branding (see Figure 1).

This marketing content is created by combining various modes of communication. Consumer engagement is built through verbal, audiovisual, and other modes of reading and digital writing as a new text.

On the other hand, message framing and color priming are recommended for web page design based on recipient characteristics (Chittaro, 2016). When it comes to digital content writing on digital economy web pages, digital content writers are motivated to consider message framing and color priming in their creative writing. It is easier to build engagement when consumers' experiences are considered. It seeks to maximize the desired results.

There is no such thing as a one-size-fits-all digital marketing strategy. When creating digital content, some factors must be considered to make the necessary adjustments. Indonesia is a large and promising market. 


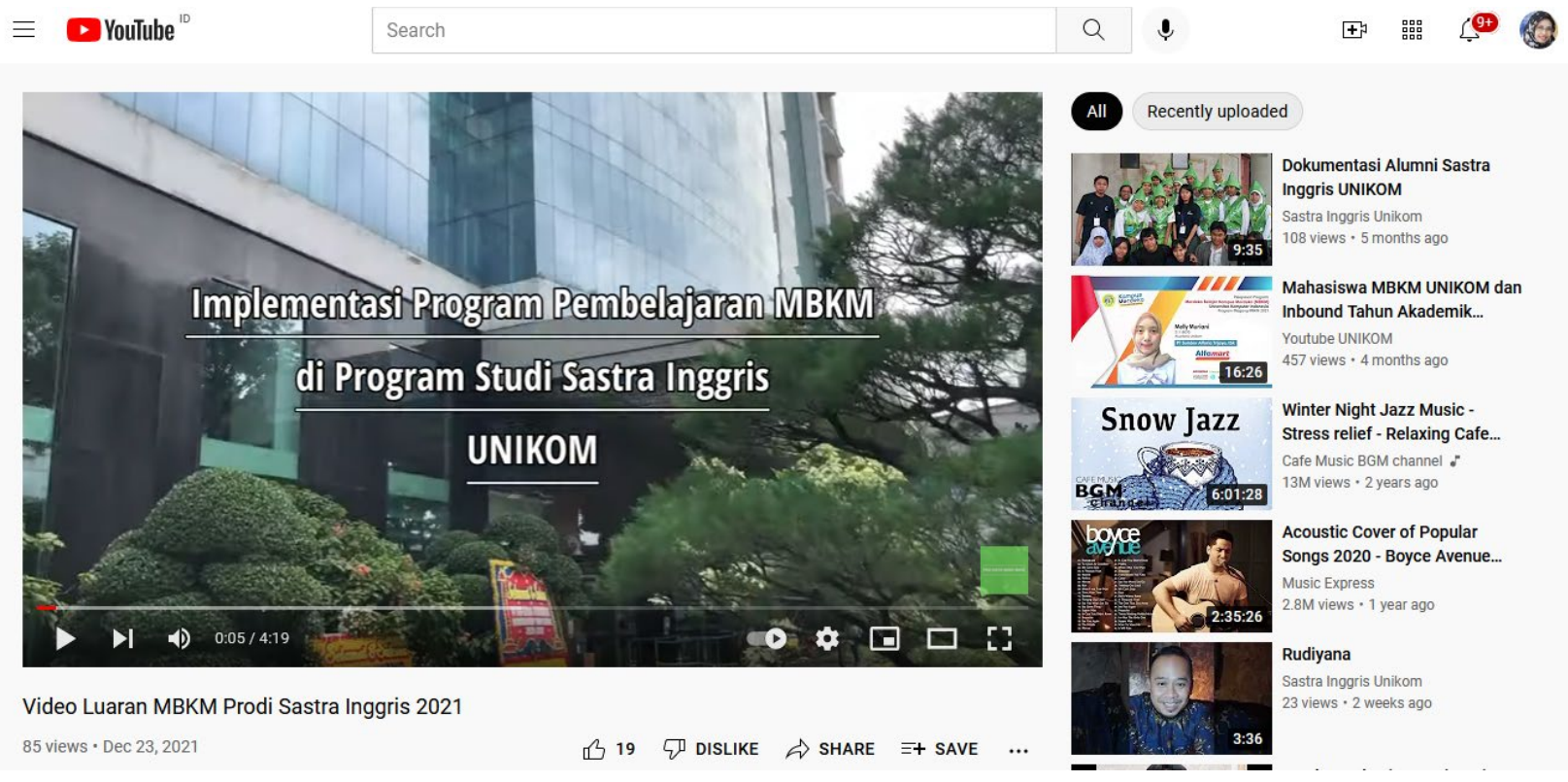

Figure 1: Modes Use in YouTube Page

Source: https://www.youtube.com/c/ SastraInggrisUnikom

To create digital content writing as a marketing strategy, a digital content writer must be proficient in both digital and language skills to communicate the firm's marketing message effectively. Of course, each digital content writer has their own method of honing their craft. Everyone understands that while digital content writing has the potential to improve a competitive strategy in today's digitalized economy, it is influenced by a dynamic shift in technological innovation and the marketplace. In some ways, creative writing exemplifies how digitalized economic activities are carried out.

\section{METHODOLOGY}

This part of the study demonstrates the need for knowledge to design a creative writing learning method. This is an alternative method for improving students' skills and opportunities for success in society. In this sense, the changing nature of works and skills has pushed Indonesian educational institutions to develop course designs that provide students with the competencies they need to master knowledge and skills in the field of digital technology. Mastering multidisciplinary fundamental concepts and understanding strategies for obtaining relevant information are components of these ideas (Moreira, 2010).

Therefore, educational institutions have conducted research, analysis, and reflections on competency teaching. The efforts result in various perspectives on what should be taught to develop $21^{\text {st }}$-century skills and competencies in university students and teachers and how it should be taught. This is part of their effort to meet the industry world's challenge.

Using the question of what should be taught as a starting point, this study described specific experiences with digital economy platforms and the writing process of professional digital content writers to identify significant learning materials. It was carried out using a crosssectional qualitative design (Phakiti et al. eds., 2018). Data on the assumptions of a group of research participants were collected using predesigned questionnaires at a single point in time, October 20-21, 2021. To assess what and how participants shared their experiences and assumptions, interaction analysis was used.

Previous researches, just as primary applied linguistic research, assisted in identifying a research gap and/or a significant problem to be addressed. Not only that, but they may help other researchers understand the methods they used. A research question and method for this applied study were established in this regard. It used principles and theories from previous studies to solve real-world learning problems. The emphasis was on how Indonesian user experiences with digital economy platforms support the writing process. 


\section{Sampling}

As previously stated, the study gathered data from a group of digital content writers in Bandung, West Java, Indonesia, all at once. The process involved ten professional writers. While collecting data, online questionnaires asked participants a variety of questions in a variety of contexts. The following questions were posed to the participants: the importance of digital literacy in the creative writing process, the role of user experiences in creative writing, specific experiences that may help them improve their writing, specific digital economy platforms they should acquire to improve their writing, and the linguistic devices to be considered.

\section{Data Processing and Analyzing}

Giulia and Bagga-Gupta's interaction analysis (2014) provided opportunities to elicit participant insight into learning material issues. It was focused on specific digital platforms, linguistic structure, context, and process. Thus, it described micro and micro levels. The validity itself lied in the manner in which appropriate justifications were set, ensuring transparency and accountability. Adapted to Holliday's argument (2016), this study carefully maintained these factors.

\section{RESULTS AND DISCUSSION}

\section{Results}

The study showed that all participants positively evaluated the importance of digital literacy and their needs to learn digital technology, with $100 \%$ agreeing that being digitally literate aided them in creating content writing. Although 10\% said his creative writing had nothing to do with his experiences with digital platforms, 90\% claimed that their experiences had an impact on their writing. However, they all agreed that familiarity with digital platforms provided advantages while writing. This prompted them to choose an appropriate digital platform, language, and style (see Table 1).

In terms of specific experiences that could help with writing digital content, the survey found that dealing with open sources and actual information is essential. Those activities are: actively reading various blogs (blog-walking) and news websites, using multiple social media, and participating in various online forums and communities.

Table 1: Digital Literacy and Creative Writing

\begin{tabular}{|c|c|c|}
\hline \multicolumn{1}{|c|}{ Questions } & Yes & No \\
\hline $\begin{array}{l}\text { 1.Is it important to learn } \\
\text { digital technology in the } \\
\text { 21st century? }\end{array}$ & $100 \%$ & $0 \%$ \\
\hline $\begin{array}{l}\text { 2.Do you need to learn digital } \\
\text { technology? }\end{array}$ & $100 \%$ & $0 \%$ \\
\hline $\begin{array}{l}\text { 3. Being literate in digital } \\
\text { technology will help you to } \\
\text { write digital content. }\end{array}$ & $100 \%$ & $0 \%$ \\
\hline $\begin{array}{l}\text { 4.Will there be any } \\
\text { disadvantages or problems } \\
\text { if you are not familiar with } \\
\text { digital platforms? }\end{array}$ & $100 \%$ & $0 \%$ \\
\hline $\begin{array}{l}\text { 5.Do you think user } \\
\text { experiences with digital } \\
\text { platforms support creative } \\
\text { writing in the digital } \\
\text { content industry? }\end{array}$ & $90 \%$ & $10 \%$ \\
\hline
\end{tabular}

Source: author's work

The listed activities provide the appropriate content for a specific audience. In this regard, some research assisted them in determining what they would write to meet specific digital market requirements. Regardless of the content, the familiarity with websites and their unique system, website, and social media features such as Call to Action (CTA) on Instagram and Search Engine Optimization (SEO) aided their writing and accessibility in Google search.

Knowing, learning, and experiencing everything related to digital issues made it easier to create great digital content. Beginning with selecting a topic that is in high demand, how to create a good article based on SEO so that the readers can easily find the article through Google search, and how to put the link on the right anchor text, how to make a call to action, and many other things.

The next question was about specific digital platforms that promote digital content writing. According to the finding, the most common digital platforms they use for writing are websites, social media, and Wattpad. WordPress, Wix, Medium, and Blogspot were among the 
most popular. They used Twitter, Instagram, WhatsApp, Tumblr, and Facebook for social media.

Many platforms are now available for creating digital writings. Platforms in personal blogs, such as Wordpress or Blogspot, are available. There are also platforms for citizen journalism, such as Kompasiana. Finally, social media platforms, such as Tumblr, Twitter, and Instagram, provide media for digital writers to write about.

Knowing the personality of readers was required to gain their engagement. As digital content writers, they became acquainted with their readers' specific interests, their background, including their age, and their way of thinking. Their investigation included a look at Google Analytics, Google performance, and Google trending. In this respect, they had the ability to define the topic, primarily the trending one. There was also concern about current information. Regardless, the characteristics of digital platforms influenced their decision to use specific engagement strategies. Every platform is distinct.

The issues - readers' interest, attention, and interaction - all contributed to the engagement. It was determined that a good engagement resulted from listening to feedback and responding appropriately. Their feedback could consist of a brief comment, praise, criticism, or a novel idea. For those, the terms "comment section," "live chat," and "contact us" are all familiar. The goal is to get readers to interact with digital content writers.

\section{Discussion}

Some studies claim that digital technology is altering the nature of writing (Connolly and Burn, 2019; Merchant, 2005; and Hicks, 2013). The unawareness of digital platforms limits the amount of information that can be grasped, which has an effect on creative writing. This is because digital platforms provide a wealth of information.

Furthermore, digital platforms may benefit firms looking to communicate their marketing message in a digital business model. Despite their ease of use, the platforms require special attention when it comes to marketing messages. When creating marketing content, a digital content writer faces some challenges. Indeed, technology is influencing the evolution of creative writing patterns for marketing strategy.
Digital platforms are not only sources of information but also a medium for digital economy marketing.

Digital literacy, initiated by user experiences with digital platforms, supports creative writing in that it invests prior knowledge in making some decisions to produce effective, highperforming content. Because each platform has its own unique characteristics, functions, and features, a digital content writer learns and chooses the best platform for his content based on its functions, writing purposes, and target readers. There is no such thing as a 'one-size-fitsall' platform in this market. The right decision can boost the content's impact.

The content as a product of creative writing simply follows a specific platform's rules (Hall, 2020). The content should ideally provide value to its readers. As a result, a content writer employs strategies to engage the readers (Segura, 2021). The strategies primarily address reader expectations and displays on each platform and mobile device to a position in the social and digital space successfully. This could potentially maximize results. At this point, consumer engagement behavior (CEB) potentially impacts brand equity (BE) of the product in level creation, extending the reach of the content and facilitating long-term brand loyalty (Zailskaite-Jakste and Minelgaite, 2021).

User experience with various digital platforms enables digital content writers to effectively and ethically master digital information in order to meet reader expectations. Using tools like Google Analytics, Google Preferences, and Google Trending, they collect all of the information, including trending topics, reader interests, and preferences. They can use these skills and knowledge to determine the best way to engage readers, the best strategic option, and the best market positioning. In this regard, the digital writers focus on innovation to create a required and expected display for each platform and mobile device. The platforms' power network effect is enhanced by increasing the performance of content writing, ensuring that economic activities involving users and customers run smoothly.

Begin by observing a popular topic, followed by examining the readers or consumers who will be reading the writing. After selecting a topic and developing a writing style and voice, content writers consider some SEO-based digital writing 
principles. Because the primary function of SEO is to increase web traffic and conversion rates, it is necessary to create a search-engine-friendly title to ensure that readers can easily find the writing via Google search. It would be extremely beneficial to include key findings and keywords in the first two sentences. As a result, the level of consumer engagement rises. Then, it appears that consistency and link building will be the next steps. Incoming links have a significant impact on a website's search engine rankings.

Furthermore, some content writing principles apply to every piece of written content to increase the impact on readers in terms of language choices, style, and voice. Bernoff (2016) stated eleven principles: write short in length and structure, use active voice and eliminate weasel words, change jargon into clarity, cite numbers effectively, use pronouns I, we, and you to invite readers to relate, move key insights up, write bold openers, cite examples, and provide signposts. These guidelines help to improve readability.

At these points, user experiences with digital platforms promote content writers to create effective, high-performing content. Educational institutions, in this case, should encourage the development of learning-teaching methods that promote the attainment of the skills. In addition, student centre learning ( $\mathrm{SCL}$ ) methods supported by the exploration of user experiences are better suited to today's students. Students prefer receiving information quickly, relying on communication technologies, performing multiple tasks, and finding information, and achieving 21st-century skills (Gonzalez-Vera, 2016). Finally, this study suggests that the educational system develops a curriculum incorporating digital economy platforms (digital technology) as a new subject and method. Today's educational system, in particular, encourages students to access and use digital information through creative writing. As a result, educational institutions must devise appropriate learning methods, such as course design, subjects, and digital learning aids.

Finally, it is suggested that creative writing skills contribute to developing a marketing communication strategy. The ability to craft a marketing message may have an impact. For example, Yamaha's marketing message "Always a step ahead" ("Semakin di depan") provides an economic sense that the product is competitive and doing things ahead of time to succeed in the motorcycle market. This message is unmistakably aimed at the Indonesian market, where people strive to be the first in everything. This influences where and to whom the message is distributed.

\section{CONCLUSION}

The integration of digital technology into the learning process encourages Indonesian educational institutions to explore new dimensions of learning-teaching methodology. Linking and matching the educational environment with the professional industry appears to be an attempt to discover new perspectives and learning materials that aid in the acceleration of achieving competencies, particularly in creative writing in digital economy platforms. To improve the quality of creative writing learning, the experiences of digital content writers in the field help Indonesian educational institutions design learning materials on creative writing in digital economy platforms. The variety and uniqueness of digital economy platforms provide fruitful experiences from which students, a human capital, can learn in-depth. Finally, digital technology has created an entirely new world for creative writing. In the end, creative writing promotes practitioners to develop a marketing communication strategy.

\section{ACKNOWLEDGEMENT}

The study for this article was funded by Universitas Komputer Indonesia. My heartfelt gratitude goes out to all scholars who continue to work on improving the learning-teaching process with the use of digital technology. The author would also like to thank the anonymous reviewers who provided constructive feedback on the current version of the article.

\section{REFERENCES}

Bearne, E., \& Wolstencroft, H. (2006). Visual approaches to teaching writing: Multimodality 5-11.

Bernoff, J. (2016). Writing without bullshit: Boost your career by saying what you mean, HarperCollins. HarperCollins

Chittaro, L. (2016, April). Tailoring web pages for persuasion on prevention topics: message 
framing, color priming, and gender. In International Conference on Persuasive Technology. 3-14. Springer, Cham https://link.springer.com/chapter/10.1007/9 78-3-319-31510-2_1

Connolly, S., and Burn, A. (2019). The Story Engine: offering an online platform for making 'unofficial' creative writing work. Literacy 53(1), 30-38.

https://onlinelibrary.wiley.com/doi/abs/10.1 111/lit.12138

Giulia, M.D., and Bagga-Gupta, S. (2014). Understanding glocal learning spaces. An empirical study of languaging and transmigrant positions in the virtual classroom. Learning Media and Technology. 39(4), 468-487.

https://www.divaportal.org/smash/record.jsf?pid=diva2\%3A7 $62638 \&$ dswid $=8884$

Goldfarb. A., Greenstein, S.M., \& Tucker, C.E. (Eds.). (2015) Economic analysis of the digital economy. University of Chicago Press. https://books.google.com/books?hl=id\&lr=\& $\mathrm{id}=6 \mathrm{jPBBwAAQBAJ} \&$ oi $=$ fnd $\& \mathrm{pg}=\mathrm{PR} 7 \& \mathrm{dq}=\mathrm{Eco}$ nomic+analysis+of+the+digital+economy\&ot $\mathrm{S}=$ _u507Exd-

R\&sig=8wAtjNveRrfqBKZEfSMMKq8Nf80

Gonzàlez Vàzquez, I. (2019). The Changing Nature of Skills and Work in the Digital Age. EUR 29823 EN, Publications Office of the European Union, Luxembourg, https://dera.ioe.ac.uk/34381/1/the_changing _nature_of_work_online_v5\%20\%28redacted \%29.pdf

Gonzalez-Vera, P. (2016). The e-generation: the use of technology for foreign language learning. New perspectives on teaching and working with languages in the digital era, 51-61. https://books.google.co.id/books?hl=id\&lr=\& id $=$ SwEYDAAAQBAJ\&oi=fnd $\& p g=P A 51 \& d q=T$ he+egeneration:+the+use+of+technology+fo $\mathrm{r}+$ foreign+language+learning\&ots $=\mathrm{vHCCBjue}$ qi\&sig=lrQK1 fMYhfAwoZAYNUHgZN4X06Q \&redir_esc=y\#v=onepage \&q=The\%20egeneration\%3A\%20the\%20use\%20of\%20techn ology\%20for\%20foreign\%20language\%20lear ning\&f=false

Hall, L. (2020). Creating Platform-Specific Social Media Content. Digital Marketing Institutes. https://digitalmarketinginstitute.com/resou rces/toolkits/member-spotlight-creatingplatform-specific-social-media-content

Halliday, M.A.K., Matthiessen, C.M.I.M. (2014). An introduction to functional grammar. Routledge. https://www.taylorfrancis.com/books/mono /10.4324/9780203783771/introductionfunctional-grammar-halliday-christianmatthiessen-michael-halliday-christianmatthiessen

Hicks, T. (2013). Crafting digital writing: composing texts across media and genres. Portsmouth, NH: Heinemann.

Holliday, A. (2016). Doing and writing qualitative research, 3rd ed., Thousand Oaks: Sage.

Kress, G. (2003). Literacy in the new media age. Routledge.

Lampinen, A., Lutz, C., Newlands, G., Light, A., \& Immorlica, N. (2018, October). Power struggles in the digital economy: platforms, workers, and markets. In Companion of the 2018 ACM Conference on Computer Supported Cooperative Work and Social Computing. 417-423. https://dl.acm.org/doi/abs/10.1145/3272973 .3273004?casa_token $=0 X W q F G h i K x c A A A A A$ :bRyUsLVu3jwieSkFmRmjQswmXpUnSXNCr KVYLeeCQ4U8x1HF4lkwm6yfYtOAalFZAcon dplGsdRJzA

Meekings, S. (2021). Utilizing Digital Literacy in the Creative Writing Classroom. Journal of Creative Writing Studies 6(1), 11-28. https://scholarworks.rit.edu/cgi/viewconten t.cgi? article $=1196 \&$ context $=$ jcws

Merchant, G. (2005). Electric Involvement: Identity performance in children's informal digital writing. Discourse: Studies in The Cultural Politics of Education, 26(3), 301314.

https://www.researchgate.net/profile/GuyMerchant/publication/228667778_Electric_I nvolvement_Identity_performance_in_child ren's_informal_digital_writing/links/00b495 370dd98d5b67000000/ElectricInvolvement-Identity-performance-inchildrens-informal-digital-writing.pdf

Merchant, G. (2007). Writing the future in the digital age. Literacy, 41(3), 118-128. https://onlinelibrary.wiley.com/doi/abs/10.1 111/j.1467-9345.2007.00469.x 
Moreira, M.A. (2010). Why Offer Information and Digital Competency Training in Higher Education? Information and Digital Competencies in Higher Education [Online monograph], Revista de Universidad y Sociedad del Conominiento (RUSC) 7(2), 2-5. https://educationaltechnologyjournal.springe ropen.com/track/pdf/10.7238/rusc.v7i2.976.p $\mathrm{df}$

Phakiti, A. et al., eds. (2018) The Palgrave handbook of applied linguistics research methodology. London: Palgrave Macmillan.

Ratajczak-Mrozek, M., Wieczerzycki, M., \& Hauke-Lopes, A. (2021). Relationship and digital competencies of individuals in value creation in the Polish digitized envitonment. Journal of Eastern European and Central Asian Research (JEECAR), 8(4), 463-480.

Segura, A. (2021). Your Social Media Partner. Mailchimp. https://mailchimp.com/resources/top-12types-of-social-media-content-to-create/

Shopova, T. (2014). Digital literacy of students and its improvement at the university. Journal on Efficiency and Responsibility in Education and Science 7(2), 26-32. https://www.eriesjournal.com/index.php/er ies/article/view/100

Zailskaite-Jakste, L., \& Minelgaite, I. (2021). Consumer engagement behavior perspective in social media: Mediating role and impact on brand equity. Journal of Eastern European and Central Asian Research (JEECAR), 8(2), 160-170.

\section{ABOUT THE AUTHOR}

Retno Purwani Sari, email: retno.purwani.sari@email.unikom.ac.id

Retno Purwani Sari, a senior lecturer of Program Studi Sastra Inggris, Fakultas Ilmu Budaya, Universitas Komputer Indonesia, Bandung, Indonesia, is gradually interested in research within Pragmastylistics covering social language functions. It brings her to the field of applied linguistic perspectives. Currently, she is working on a research project on how technology motivates attitude and behavior change concerning language style and preference. Persuasive technology keeps her focus on the language functions. In practice, she deals with language functions studying how technology initiates language performance change. 